\title{
TINJAUAN AL-QURAN DAN PRINSIP PEMBEBANAN DALAM PENENTUAN DIMENSI KESTABILAN PONDASI BANGUNAN
}

\author{
Agung Sedayu \\ Junsan Teknik Arsitektur Fakultas Sains dan Teknologi UIN Malang \\ Jin. Gajayana 50 Malang, Hp. 08155172619 , email: agung_resta @yahoo.co.jd
}

\section{Abstract}

Foundation is a part of building construction having function continuously to support entire or all the building burden to ground. One of the factor of buildingcontruction should be supported by the sturdy foundation, and sturdy foundation depend on his compiler composition and dimension of foundation. Therefore it is needed the calculations of foundation so that we get well guaranted of his stability. Besides that, ground factor also have stability of structure, because the ground sustain the foundation and place where burden given by foundation. Power factor support the ground against the foundation action is highly varied, it is depend on composition and nature of ground, information concerning energy number support of this ground can be shown passing investigation of ground. To guarantee security in a building one of the among others is to looking for comparison between foundations and well-balanced ground. The dimension of foundation must be enough and fit with the power of ground. Determination of building foundation is very influenced by energy support the ground. And energy support the ground depict strength of ground to accepted burden. Energy support the ground is very influenced by character, nature, type, structure, formation, and component compiler of ground, besides also usage of foundation type is also influenced by contour, ground water face and topography. energy 
support the ground explained by some concept or theories, among others is Terzaghi theory and accepted encumbering principle or apply at the foundation structure. From both this concept determinable of enough and stable dimension of strength sustain a building. the Foundation dimension is reckoned by the minimum or smallest measure or dimension, but have ever been optimal to sustain the burden befall it.

Key words: foundation, construction, dimension, stability, building

\section{Pendahuluan}

Firman Allah swt:

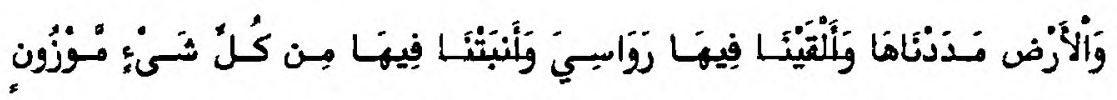

Dan Kami telah menghamparkan bumi dan menjadikan padanys gunung-gunung dan Kami tumbuhkan padanya segala sesuatu menurut ukuran. (QS. al-Hijr: 19).

Dalam perencanaan dan pelaksanaan struktur dan konstruksi bangunan dilakukan dengan beberapa tahap dan metode. Tahapdan metode perencanaan dan pelaksanaan tersebut dilakukan dengan terukur dan melalui perhitungan yang sangat cermat, agar struktur bangunan tersebut tidak hanya aman namun juga handal dalam melayani manusia atau usernya. Hasil perencanaan dan pelaksanaan suatu konstruksi bangunan meliputi (Canonica, 1998: 11):

1. Kurang memenuhi ukuran atau takaran semestinya, yang menyebabkan struktur tersebut rapuh dan tidak kuat (tidak stabil).

2. Sesuai ukuran standar, berdasarkan perhitungan dan pertimbangan struktur sesuai ukuran yang semestinya. Bangunan stabil dan kokoh, namun biaya relatif murah disesuaikan spesifikasi bangunan dan standar stabilitasnya.

3. Melebihi ukuran atau standar, yang berakibat borosnya struktur bangunan tersebut. Memang kuat dan handal namun tidak mempertimbangkan aspek biaya dan waktu pelaksanaan konstruksi. 
Bangunan memiliki elemen struktural dan elemen nonstruktural: Elemen struktural merupakan elemen yang mengemban tugas menyokong seluruh beban bangunan dan yang mendukung bangunan supaya berdiri tegak dan kokoh, sedangkan elemen nonstruktural adalah elemen pemanis bangunan agar tampil indah dan estetis, sehingga memberi makna secara arsitektural dan artistik bangunan.

Dari sekian elemen struktural bangunan pondasi sangat memegang peranan penting dalam bangunan, sebagai penyokong beban terakhir. Selain pondasi elemen struktural bangunan yang lain adalah kolom atau tiang, balok, rangka atap, plat lantai, dinding pemikul, dan lain-lain.

\section{Pondasi Bangunan}

Pondasi (Foundation) disebut juga Pandemen (fundament) atau struktur bangunan bagian bawah (Sub Structure). Pondasi memiliki pengertian suatu bagian dari konstruksi bangunan yang bertugas mendukung seluruh beban bangunan dan meneruskan beban bangunan atas (Upper Structure/Super Structure) ke dasar tanah yang cukup kuat men-dukungnya (Puspantoro, 1996: 79). Dalam teori arsitektur pondasi dan lantai merupakan kaki bangunan selain bangunan memiliki badan (dinding) dan kepala (atap) (Soemardiono, 2002: 14).

Pondasi sangat berkaitan erat dengan tanah yang menopangnya, karena prinsip dari pondasi adalah meneruskan seluruh beban bangunan ke tanah. Pondasi sangatlah berpengaruh dalam menentukan kestabilan struktur bangunan, dan juga sebagai salah satu pengokoh bangunan.

Kestabilan pondasi sangat dipengaruhi oleh komposisi bahan penyusunnya dan dimensi atau ukuran pondasi tersebut. Penyusun dan dimensi pondasi sangatlah beragam bergantung jenis, macam, dan kuantitas beban bangunan yang diterima pondasi. 


\section{Bahan Penyusun Pondasi}

Bahan penyusun pondasi umumnya adalah material yang mampu menahan beban tekan dan gaya geser, material yang banyak dipakai di lapangan antara lain adalah batu kali, batu, batu bata, beton bertulang dan lain sebagainya (Laulu, 1983: 42). Untuk beton bertulang dipakai campuran semen, kerikil, pasir, air yang di dalamnya terdapat besi atau baja tulangan. Komposisi batu kali sangat banyak dipakai dalam pembuatan pondasi untuk rumah-rumah sederhana dengan bangunan satu hingga dua lantai. Material penyusun pondasi yang banyak dipakai dalam proyek-proyek pembangunan adalah batu, besi-baja sebagai tulangan, dan semen. Ketiga material ini sangat kokoh dan kuat, diantara ketiganya saling mendukung apabila disusun menjadi bahan struktur komposit.

Firman Allah swt:

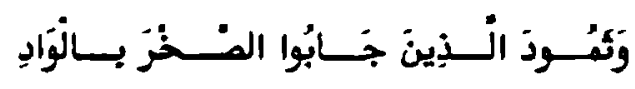

Dan kaum Tsamud yang memotong batu-batu besar di lembah (QS. al-Fajr: 9).

Dijelaskan dalam terjemah al-Quran bahwa lembah tersebut terletak di bagian utara Jazirah Arab antara kota Madinah dan Syam, mereka memotong-motong batu gunung untuk membangun gedung-gedung tempat tinggal mereka dan ada pula yang melubangi gunung-gunung untuk tempat tinggal mereka dan tempat berlindung. Batu banyak dipakai oleh manusia sejak jaman dahulu sebagai bahan penyusun bangunan, dicontohkan kaum Tsamud yang sangat ahli dalam bangunan, mereka menggunakan batu-batu gunung sebagai material penyusun bangunan, dan menempatkan batu sebagai material dominan dan utama sebagai bahan struktur bangunannya.

Bahan besi adalah material yang sangat kuat yang bermanfaat demi kepentingan umat manusia, salah satunya sebagai material struktural maupun nonsiruktural bangunan. Sebagaimana dalam Firman Allah swt 


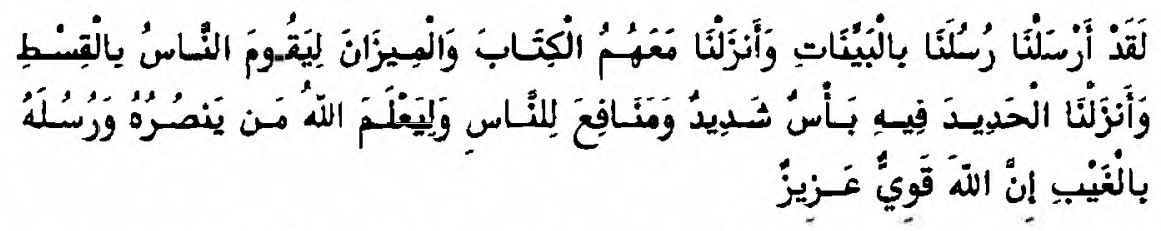

Sesungguhnya Kami telah mengutus Rasul-rasul Kami dengan membawa bukti-bukti yang nyata dan telah Kami turunkan bersamia mereka Al kitab dan neraca (keadilan) supaya manusia dapat melaksanakan keadilan. dan Kami ciptakan besi yang padanya terdapat kekuatan yang hebat dan berbagai manfaat bagi manusia, (supaya mereka mempergunakan besi itu) dan supaya Allah mengetahui siapa yang menolong (agama)Nya dan rasul-rasul-Nya Padahal Allah tidak dilihatnya. Sesungguhnya Allah Maha kuat lagi Maha Perkasa (QS. al-Hadid: 25)

\section{Jenis Pondasi}

Berdasarkan kedalamannya pondasi dibagi dua bagian (Gunawan, 1993:10), yaitu:

a. Pondasi Dangkal (Shallow Foundations), adalah jenis pondasi yang dasarnya terletak tidak terlalu dalam dari permukaan tanah atas. Dapat dikerjakan dengan alat sederhana oleh tenaga manusia dengan kedalaman pondasi dari muka tanah adalah kurang atau sama dengan lebar pondasi ( $\mathrm{Dd}$ " B).

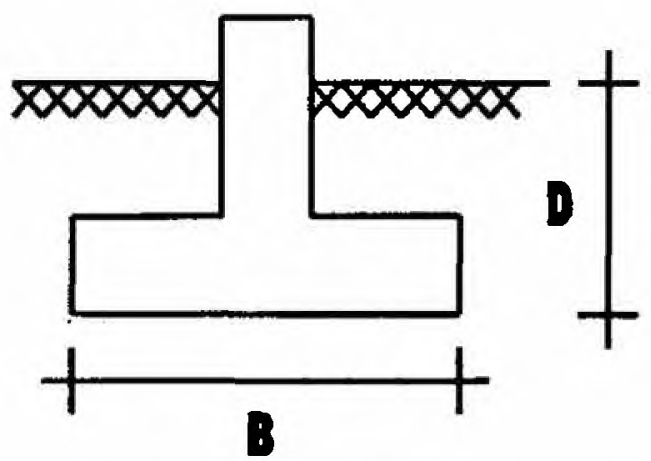

Gambar 1. Rasio Dimensi Pondasi Dangkal (Gunawan, 1993: 12)

Ulul Albab, Vol. 9 No. 1, 2008 
Pondasi dangkal ini dibagi lagi menjadi:

1. Pondasi Menerus (Continuous Footing), dipakai dengan kedalaman 0,80 $-1,20 \mathrm{~m}$ dari permukaan tanah.

2. Pondasi Telapak atau Setempat (Individual Footing), dipakai pada kedalaman tanah lebih dari 1,20 m dari muka tanah, berdasarkan bahan pembentuknya dibedakan dua macam, yakni Plat beton bertulang (Pondasi Telapak - Voet Plat) dan Pilar pasangan batu-kali, selain itu terdapat pula pondasi sumuran.

3. Pondasi Gabungan, merupakan pondasi plat yang mendukung kolom lebih dari satu. Pondasi ini dipakai bila luas tanah untuk bangunan sangat terbatas.

4. Pondasi Plat, merupakan pondasi yang dibuat berupa plat tebal dengan perkuatan balok-balok dari beton bertulang kedap air, dipasang di bawah seluruh luas bangunan, dapat dimanfaatkan sebagai ruang basement di bawah tanah.

b. Pondasi Dalam (Deep Foundations), adalah jenis pondasi yang dipakai pada kedalaman lebih dari $6,00 \mathrm{~m}$ dari permukaan tanah. Dikerjakan dengan peralatan berat dengan kedalaman pondasi dari muka tanah adalah lima kali lebar pondasi (Dd" 5B).

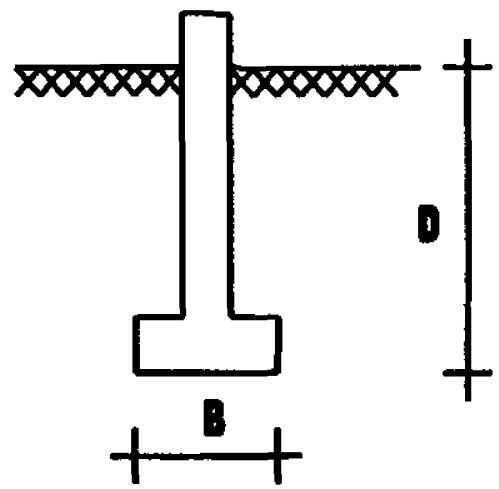

Gambar 2. Rasio Dimensi Pondasi Dalam (Gunawan, 1993: 14)

Ulul Albab, Vol. 9 No. 1, 2008 
Jenis pondasi ini antara lain adalah (Puspantoro, 1996: 81) :

1. Pondasi Tiang Pancang, dengan tiang yang terbuat dari batang kayu, baja atau beton bertulang.

2. Pondasi Sumur Bor (Bored Pile), dengan cara membor tanah kemudian diberi cor beton.

Selain pondasi-pondasi tersebut di atas masih terdapar jenis dan macam pondasi lain dengan banyaknya hasil temuan pondasi baru yang lebih canggih dan didukung oleh teknologi yang mutakhir, misalnya pondasi cakar ayam, gasing, sarang tawon, dan lain-lain.

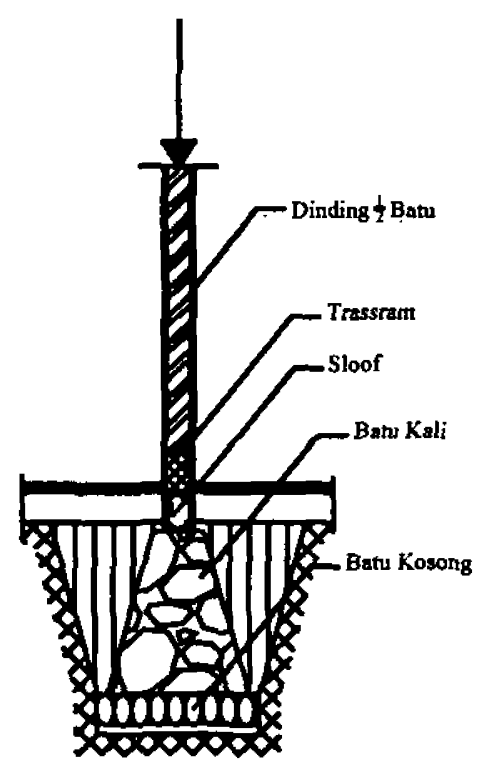

Gambar 3. Pondasi Batu Kali

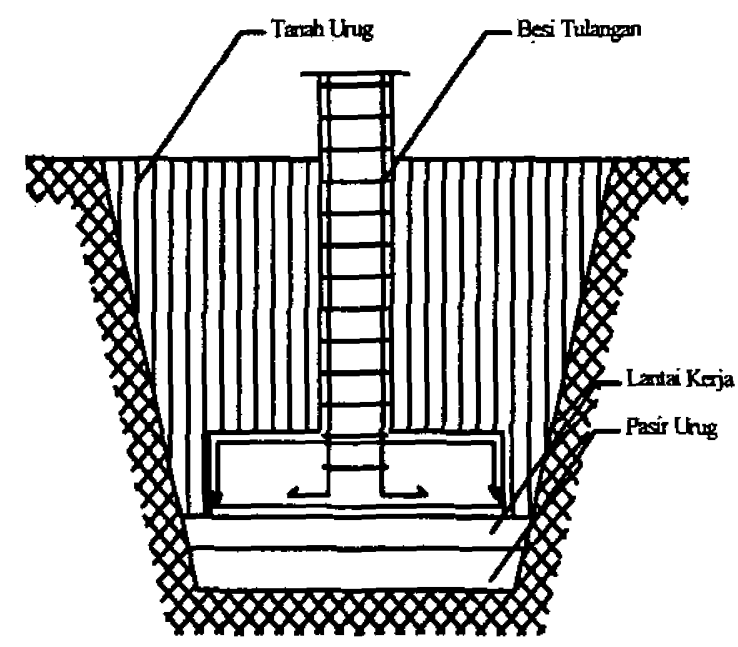

Gambar 4.Pondasi Plat Beton

\section{Tanah Sebagai Bahan Pondasi}

Tanah merupakan salah satu bahan pondasi yang menopang beban yang diberikan pondasi kepadanya, jadi tanah adalah tahap akhir dalam proses pembebanan struktur bangunan. Tanah memiliki karakter dan komposisi yang berbeda-beda, dan ini mempengaruhi kuat tahan tanah 
tersebut terhadap beban dari pondasi. Lapisan tanah yang layak ditempati pondasi adalah lapisan tanah padat dan keras agar tidak terjadi gejala penurunan (settlement) pada bangunan. Letak lapisan tanah keras berbedabeda di lain tempat, oleh karena itu diperlukan penyelidikan lapangan (Soil Investigation) dan penelitian laboratorium mengenai tanah tempat dimana bangunan hendak didirikan (Laulu, 1983: 27).

\section{Teori Terzaghi}

Agar sebuah pondasi mampu menopang struktur yang ada di atasnya, maka diperlukan suatu perhitungan yang cermat dan teliti. Seperti yang telah dijelaskan di atas bahwa kakuatan pondasi bergantung pada dimensi atau ukuran pondasi yang disesuaikan dengan beban yang dia terima. Dengan perhitungan tersebut maka kekuatan yang diperlukan menjadi terukur.

Terzaghi seorang ahli konstruksi pondasi dari Jepang memberikan konsep perhitungan kekuatan pondasi dengan memperhatikan daya dukung tanah. Tanah merupakan tahap terakhir beban ditanamkan oleh pondasi, jadi tanahlah yang berhadapan langsung dengan pondasi bangunan. Terzaghi memberikan konsep yang terkenal ini berupa rumus atau formula, yang dikenal dengan nama rumus daya dukung tanah Terzaghi (Lucio Canonica, 1998: 15) :

$$
\mathrm{q}_{\mathrm{u}}=\mathrm{c} \cdot \mathrm{N}_{\mathrm{c}}+\mathrm{q} \cdot \mathrm{N}_{\mathrm{q}}+0,5 \gamma \cdot \mathrm{B} \cdot \mathrm{N}_{\gamma}
$$

$q_{u}=$ daya dukung tanah ultimate

$\mathrm{c}=$ kohesi tanah

$\mathrm{B}=$ lebar pondasi

$\mathrm{D}=$ Kedalaman pondasi

$\mathrm{q}=\boldsymbol{} \mathrm{D}$ (surcharge load)

$\gamma=$ besar volume tanah

Teori Terzaghi tersebut berlaku untuk pondasi dangkal (Dd"B) dan berlaku pada kondisi 'general shear failure' yakni penurunan oleh sebab gaya 
geser pondasi dengan tanah dan berlaku untuk jenis-jenis tanah tertentu. Rumus Terzaghi di atas adalah untuk pondasi menerus, disamping itu juga terdapat rumus Terzaghi yang lain yang dipakai pada jenis-jenis tanah tertentu.

\section{Prinsip Pembebanan Pondasi}

Selain teori Terzaghi untuk menentukan ukuran pondasi adalah dengan rumus pembebanan yang diterima pondasi tersebut, teori ini juga merupakan salah satu teori daya dukung tanah (Lucio Canonica, 1998:11).

Rumus tersebut digunakan untuk mencari lebar bawah pondasi, baru kemudian kita cari ukuran tinggi dari luas atau volume bentuk dasar pondasi. Rumus pembebanan tersebut ditunjukkan di bawah ini:

$$
F=\frac{P}{T}
$$

$\mathrm{F}=$ ukuran luas pondasi yang dibutuhkan

$\mathrm{P}=$ beban bangunan yang diterima pondasi

$\mathrm{T}=$ daya dukung tanah yang diijinkan (ultimate)

Pada tulisan ini, perhitungan pondasi dilakukan pada pondasi batu kali dan plat beton karena kedua pondasi tersebut sering dan banyak dipakai pada bangunan rumah tinggal dan perkantoran sederhana dengan 1-3 lantai.

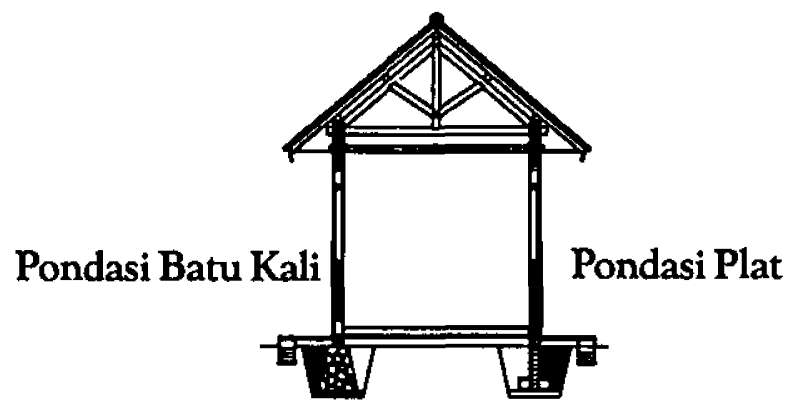

Gambar 5. Potongan bangunan dengan pondasinya

Ulul Albab, Vol. 9 No. 1, 2008 


\section{Simpulan}

Kestabilan bangunan sangat ditentukan oleh kestabilan pondasinya, karena pada prinsipnya pondasi bangunan adalah bagian terakhir bangunan yang menopang seluruh beban dan diteruskan ke tanah. Pondasi sangat berkaitan dengan tanah yang dihadapinya, jadi secara umum pondasi sangat dipengaruhi oleh bahan dan komponen pondasi, ukuran pondasi, dan daya dukung tanah. Daya dukung tanah ini sangat pula dipengaruhi oleh komposisi, jenis, sifat, dan karakter tanah tersebut. Daya dukung tanah ditunjukkan oleh angka mutlak, dimana apabila angka tersebut besar, maka besar pula daya dukung tanah tersebut, dan ini baik untuk tanah yang aman bagi pondasi dengan spesifikasi tertentu.

Penentuan pondasi sangat ditentukan oleh beberapa hal di atas, termasuk juga ketinggian dan kontur suatu lahan tanah. Penentuan dimensi pondasi ini dapat dihitung dan dicari dengan menggunakan metode Teori Terzaghi dan Prinsip Pembebanan yang berlaku dalam struktur bangunan tersebut. 


\section{Daftar Pustaka}

Puspantoro, Benny. 1996. Konstruksi Bangunan Gedung Bertingkat Rendah. Yogyakarta: Penerbitan Universitas Atmajaya

Soemardiono, Bambang. 2002. Teori Arsitektur. Surabaya: ITS Press.

Sadji. 2000. Konstnuksi Statis Tertentu. Surabaya: ITS Press.

Gunawan, Rudy. 1993. Pengantar Teknik Pondasi.Yogyakarta: Kanisius.

Laulu, L, dkk. 1983. Mekanika Tanah dan Teknik Pondasi. Jakarta: Pradnya Paramita.

Canonica, Lucio. 1998. Memahami Pondasi. Bandung: Angkasa.

Sunggono, KH. 1995. Buku Teknik Sipil. Bandung: Nova.

Q.S. al-Fajr: 9

Q.S. al-Hadiid : 25

Q.S. al-Hijr : 19 